\title{
El Mal Querer como álbum visual: simbología de lo español, apropiación y narrativa transmedia en los videoclips de Rosalía
}

\section{Ana María Sedeño-Valdellos ${ }^{1}$}

Recibido: 11/01/2020

Aprobado por pares: 16/03/2020
Enviado a pares: $11 / 01 / 2020$

Aceptado: 18/03/2020

DOI: 10.5294/pacla.2021.24.2.6

Para citar este artículo / to reference this article / para citar este artigo Sedeño-Valdellos, A. M. (2021). El Mal Querer como álbum visual: simbología de lo español, apropiación y narrativa transmedia en los videoclips de Rosalía. Palabra Clave, 24(2), e2426. https://doi.org/10.5294/pacla.2021.24.2.6

\section{Resumen}

La narrativa transmedia supone una nueva configuración de los proyectos culturales mediados a través de los canales de comunicación, que combina los tradicionales (televisión, radio, medios impresos) con los novedosos (medios online, redes sociales). En ellos se trasciende la gestión única de los mensajes, se planifica de forma que adquieran sentido a través de los medios y se diversifican los momentos de liberación de estos mensajes. El álbum visual, como heredero del álbum conceptual de rock, establece un formato extendido en la idea de videoclip musical, donde la unidad y la coherencia de los discursos visuales son rasgos primordiales. El artículo examina los motivos visuales a modo de símbolos reconocibles de la tradición española y la apropiación cultural que hace de ellos el álbum visual El Mal Querer de Rosalía (2018). El análisis se enmarca en una reflexión sobre el videoclip actual y otros conocidos álbumes visuales.

$1 \bowtie$ https://orcid.org/0000-0003-3897-2457. Universidad de Málaga, España. valdellos@uma.es 


\section{Palabras clave (Fuente: tesauros de la Unesco)}

Estudios culturales; medios de comunicación de masas; música popular; discurso; estética; música pop; grabación en disco; interpretación musical. 


\section{El Mal Querer as a Visual Album: Spanish Symbology, Appropriation, and Transmedia Narrative in Rosalía's Music Videos}

\section{Abstract}

Transmedia narrative entails a new configuration of cultural projects mediated by communication channels, combining traditional (television, radio, print media) and contemporary (online media, social media) ones. In them, the single management of messages is transcended and planned so that it makes sense through the media, and the timing of message delivery is diversified. As an heir to the conceptual rock album, the visual album establishes an extended music video format, whose prominent features are unity and coherence of the visual discourses. The article examines the visual motifs as recognizable symbols of the Spanish tradition and cultural appropriation by Rosalía's visual album El Mal Querer (2018). The analysis is part of a reflection on the current music video and other well-known visual albums.

\section{Keywords (Source: Unesco Thesaurus)}

Cultural studies; mass media; popular music; speeches; aesthetics; pop music; disc recordings; records; musical performances. 


\section{El Mal Querer como álbum visual: simbologia do espanhol, apropriação e narrativa transmídia nos videoclipes de Rosalía}

\section{Resumo}

A narrativa transmídia indica uma nova configuração dos projetos culturais mediados por canais de comunicação, que combina os tradicionais (televisão, rádio, meios impressos) com os novos (meios digitais, redes sociais). Neles, transcende-se a gestão única das mensagens e planeja-se de forma que adquira sentido através dos meios e diversificam-se os momentos de liberação dessas mensagens. $O$ álbum visual, como herdeiro do álbum conceitual de rock, estabelece um formato estendido na ideia de videoclipe, em que a unidade e a coerência dos discursos visuais são características primordiais. Neste artigo, examinam-se os motivos visuais enquanto símbolos reconhecíveis da tradição espanhola e da apropriação cultural que o álbum El Mal Querer de Rosalía (2018) faz deles. A análise está delimitada em uma reflexão sobre o videoclipe atual e outros conhecidos álbuns visuais.

\section{Plavras-chave (Fonte: tesauro da Unesco)}

Estudos culturais; meios de comunicação de massas; música popular; discurso; estética; música pop; gravação em disco; interpretação musical. 


\section{Introducción y aproximación metodológica: Transmedia e industria musical}

Las narrativas transmediales se diferencian de las tradicionales en la apertura de canales de recepción y en la diversidad de públicos objetivos, afrontados estratégicamente desde diversos medios: ello responde a lógicas narrativas lejanas a la clásica, de distribución en un único medio y cierre completo de la línea de la trama al final del consumo del formato. Por el contrario, en lo transmedial se trata de dispersar contenido: se produce la "conversión de un sistema discreto de mediación de acceso restringido en un sistema continuo de acceso potencialmente universal” (Carreras et al., 2013, p. 544). En este contexto las narrativas transmediales componen un contexto multidimensional de recursos que permiten multiplicar la presencia del productor/creador o responsable en la atención de la audiencia, aprovechando cada una de las posibilidades de los medios involucrados.

El género audiovisual más consumido en YouTube, el videoclip musical, resulta un lugar especial para la interconexión de contenidos, para lo que adquiere variados formatos, con el objetivo de plegarse a los diversos objetivos de una estrategia multidireccional donde quepan la producción industrial, la profesional, la amateur... El reciente formato del álbum visual puede insertarse en esta situación: cada vez más se decide su concepción y realización para construir una narrativa de la estrella de pop music, una narrativa personal. Sus mayores costos concluyen con la necesidad de planificar la liberación de cada una de las piezas para adaptarlas al mercado cultural, en permanente transformación.

En este texto nos proponemos realizar una aproximación de análisis textual al álbum visual de Rosalía El Mal Querer (2018), con la doble finalidad de caracterizarlo como proyecto inserto en la tradición de las narrativas transmedia, así como describir su iconografía, que se asienta sobre la apropiación de símbolos culturales reconocidamente españoles.

Con el objetivo de conducir este acercamiento a este trabajo musical concreto caracterizándolo como álbum visual, entendido como complejo mediático, se ha decidido elegir herramientas variadas, abiertas y aglutina- 
doras de posibilidades epistémicas. Esta apertura metodológica es la propia que domina los estudios visuales y la perspectiva de la ecología de los medios, donde ya se asumen los caracteres de los objetos mediáticos como interdisciplinares, de circulación global y recepción masiva, pero especializada y con objetivo de desarrollo transmedia, esto es, las historias, los proyectos se conciben y plantean con un programa de difusión totalizadora de contenidos, esperando el máximo de vida útil. A esto se refiere Lizarazo Arias así: "los ámbitos hermenéuticos ofrecen un nuevo escenario para pensar el mundo de la imagen, donde no solo nos interesan las estructuras, sino los movimientos humanos y sociales que dichas formas icónicas cristalizan y ponen en juego" (2004, p. 23). En esta unión de herramientas hermenéuticas con análisis iconográfico de símbolos y propuestas visuales en los vídeos de este álbum se encuentra el núcleo del planteamiento metodológico que se presenta.

\section{Videoclip y álbum conceptual como antecedentes}

La música no ha aparecido especialmente en los estudios sobre comunicación transmedia, sin embargo, la promoción de trabajos musicales supone seguramente uno de los ejemplos paradigmáticos, si se consultan aproximaciones como la de Hawkins y Richardson (2007), autores que pretenden justificar la estética audiovisual de los vídeos y los documentales como una discusión de agencia y una representación pop que da sentido a la performance: estos formatos crean un bagaje para la actuación en directo que permite una construcción en curso de la identidad del músico o de la banda y un conexión entre el pasado y el futuro del artista. Este hilo conductor entre las imágenes mediáticas y las actuaciones en directo es explicado como construcción conceptual globalizadora por Dixon, quien asegura que la performance digital (con la que da nombre a toda la presencia de un artista musical en medios digitales) intenta erradicar la distinción entre mente y cuerpo, "en el sentido de que los artistas de performance exploran y promulgan sus autonomías e interioridades holísticas, y no simplemente su corporeidad" (2004, p. 215).

Desde aquí, para abordar el análisis del álbum visual es necesario introducir un componente esencial, núcleo de la naturaleza del video musi- 
cal: la necesidad de construcción visual del estrellato del grupo o artista, más allá de su presentación física en concierto o en directo supone el origen del videoclip conceptual, fruto de la "carencia visual” que según Simon Frith (1988) caracteriza la música popular y da forma al hecho de la narrativa laxa que describe Vernallis (2008): se encuentra aquí el centro de la condición no narrativa del videoclip, herencia que llega a este formato desde las prácticas videoartísticas, el arte de acción, el happening y el arte de vanguardia. En diversos momentos se ha descrito este tipo, bien como videoclips antinarrativos o apelando a un nivel poliédrico que, "expresa el desarrollo temporal en favor de una espacialización: el video concretamente gira en torno a un escenario, personaje o escenas, compone/se interna en un espacio, narra un espacio o atmósfera, sugiere presencia simultánea en varios lugares o detalles, provoca la sensación del presente continuo" (Leguizamón, 1998). Por su parte, Kleiler y Moses hacen distinción entre videoclips cinemáticos y videoclips fotográficos (1997, pp. 26-30), aquellos que usan aspectos de puesta en escena o de tratamiento visual y creativo de la imagen. Es decir, el videoclip conceptual se aleja de la narrativa tradicional clásica y al mismo tiempo instituye un modo alternativo de presentación discursiva que, por alguna razón, se ajusta mejor a la presentación mediática de la música popular, más abierta estéticamente, basada en asociaciones y fórmulas de edición y composición de imagen alejadas de reglas de la transparencia narrativa o reglas del eje del modo de representación institucional (RI) de Noël Burch. De ahí que podamos sugerir como rasgos particulares del videoclip conceptual la ausencia de narrativa clásica, el alejamiento de la fórmula de videoclip performance (basado en el concierto) y la tendencia a la búsqueda de fórmulas de visualización musical o sincronía musicovisual que llegan desde los parámetros de la cámara, la composición digital de la imagen, la edición rítmica o los efectos visuales.

Con estas técnicas, el videoclip construye una especie de cuadros vivos o tableaux vivants, en los que la acción aparece detenida, como pausada, estancada en acciones atomizadas, de escaso contenido narrativo o anecdóticas. El tableau vivant fue introducido en la creación audiovisual ya en la etapa del cine mudo como escenas estáticas y frontales con un mínimo contenido de acción, que actuaban por acumulación o suma, sin obligado 
encadenamiento narrativo. Estos cuadros frontales suponen composiciones pictóricas en un sentido amplio, tomas descriptivas con un movimiento cinemático mínimo que refieren a lo teatral, a lo gestual de la tradición pictórica burlesca y de otras disciplinas de las bellas artes.

Como forma de transcender esta necesidad de experimentación estética que ha ofrecido este formato a la música popular, el pop y rock con ambición de transformación y éxito en ventas, creó hace unas décadas el álbum conceptual: este tipo de trabajo discográfico recoge toda una tradición de activismo y resistencia en letras, actitudes y renovación artística que se encuentra en la música popular de los últimos sesenta años. Coincidiendo con proyectos complejos normalmente de grupos emblemáticos como The Beatles (St Pepper's Lonely Hearts Club Band), David Bowie (The Rise and Fall of Ziggy Stardust and the Spiders from Mars, 1972), Pink Floyd (The Wall, 1982) y más recientemente Coldplay (Mylo Xyloto, 2011), Nine Inch Nails (Year Zero, 2011), y varios del grupo Radiohead, en el álbum conceptual se han constatado variados modos. Letts (2010), en How to Disappear Completely: Radiohead and the Resistant Concept Album, distingue tres clases de álbumes conceptuales: el narrativo, que cuenta con una trama explícita e implícita y unos personajes definidos; el temático, en el que no hay una historia, pero sí una cohesión a través de un tema, y el "álbum resistente", en el que sus productores y artistas se niegan a permitir una interpretación fácil o unívoca. Este es el caso de los clips de Kid A, Ok Computer o The Bends del grupo Radiohead, analizados por Letts, que concluye que "interpretar Kid A se convierte en una metáfora para sobrevivir en la sociedad moderna" (2010, p. 94).

Creemos que estas clases se han traspasado y mezclado en el álbum visual a través de las estrategias transmedia, hasta convertirse en una tradición minoritaria orientada a explotar la relación del álbum con los contenidos de otros medios y las redes sociales: se trata de una modificación del acento de lo narrativo y su paso a lo visual, con historias construidas con retazos de escenarios, personajes, anécdotas o gags visuales y escenas visualmente poco complejas, donde los músicos elaboran su relación con el espectador de forma abierta y a largo plazo. En otras palabras, el transmedia 
se institucionaliza como el tipo de proyecto que gestiona a medio y largo plazo estas fórmulas de interrelación entre historias y contenidos. En este contexto se encuentra el álbum visual, como formato totalizador y contenedor de esta tradición, a lo que se añade la posibilidad de distribución en redes sociales de los contenidos oficiales y los producidos por usuarios o fans. Harrison proporciona una definición de álbum visual: "un producto audiovisual que tiene una relación directa con la música de un álbum del mismo artista. La duración del álbum es mayor que la duración estándar de 3-5 minutos, y están presentes fuertes relaciones textuales y visuales para crear continuidad en todo el álbum” (2014, pp. 16-17; traducción propia).

Con el objetivo de definir el presente y futuro del artista, y como ha apuntado Harrison, los álbumes visuales necesitan construir un discurso sonoro y visual unitario a la vez que heterogéneo: "el álbum visual crea continuidad a través del uso de leitmotivs visuales, que aluden a las narrativas ficcionales y personales" (Harrison, 2014), a través de motivos visuales: tema "cuyo propósito es representar o simbolizar una persona, objeto, lugar, idea, estado de la mente, fuerza sobrenatural o cualquier otro ingrediente en un trabajo dramático" (Chandler y Munday, 2011).

Como se analizaba con Let England shake de PJ Harvey, la liberación de los vídeos suele ser global y estratégica desde su concepción,

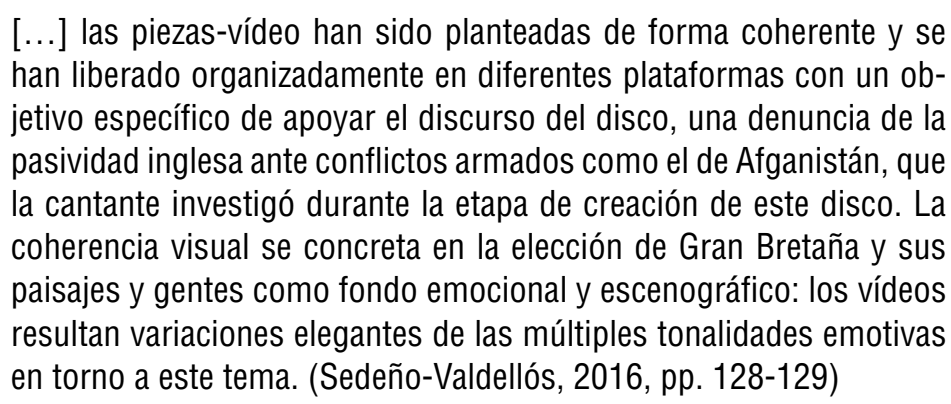

Muy controvertidos y de referencia son los álbumes visuales que la artista estadounidense Beyoncé tiene en el mercado, Beyoncé (2013) y Lemonade (2016). El segundo completamente concebido como un álbum visual moderno, con una pensada estrategia transmedia de concepción única, 
pero de liberación diferenciada como película en plataformas online (Tidal) y como vídeos en redes sociales. Toda esta estrategia construye un imaginario dicotómico de empoderamiento y objetualización (Hansen, 2017), que suma "el viaje de cada mujer al autoconocimiento y la curación" con un discurso político negro donde "la lógica del estilo se manifiesta a través de las superficies culturales en la vida cotidiana [para] reforzar en términos de experiencia compartida" (Ball, 2016).

\section{Rosalía y el álbum visual: estrategias de apropiación y transmedia}

La cantante Rosalía es una de las artistas españolas de mayor proyección internacional en los últimos años. Sus colaboraciones en forma de canciones a dúo y vídeo con C Tangana, James Blake, J Balvin, Ozuna lideran las visualizaciones en YouTube, alcanzando 47 millones en la semana del estreno de Con Altura -con J Balvin- del 24 de junio al 3 de julio de 2019. La artista ha publicado dos álbumes: Los Ángeles (2017) y El Mal Querer (EMQ) (2018). El primero destaca por el descubrimiento de la capacidad de emplear el flamenco para mezclarlo con todo tipo de géneros, por sus colaboraciones y sus versiones de clásicos. Por su lado, EMQgenera una transición específica al trap en su hibridación con el flamenco, especialidad en la que se graduó la artista en el Conservatorio Superior de Cataluña, aunque ella misma discute y problematiza esta influencia.

Como álbum visual, $E M Q$ se encuentra en construcción pues solo existen en vídeo los episodios: Malamente (cap. 1. Augurio), Que no salga la luna (cap. 2. Boda), Pienso en tu mirá (cap. 3. Celos), De aquí no sales (cap. 4. Disputa), Reniego (cap. 5. Lamento), Preso (cap. 6. Clausura), Bagdad (cap. 7. Liturgia), Di mi nombre (cap. 8. Éxtasis), Nana (cap. 9. Concepción), Maldición (cap. 10. Cordura) y A ningún hombre (cap. 11. Poder).

A pesar del sello independiente del disco y su promoción, alejada del apoyo de una discográfica tradicional, el trabajo estuvo concebido y desarrollado por la producción (a cargo de la propia Rosalía y de El Guincho) como una campaña entera de comunicación para la creación (para la cons- 
trucción) de un storytelling musical, de un relato propio, desde el imaginario de la novela anónima Flamenca, escrita en el siglo XIV, y que relata la historia de violencia y la lucha de una mujer por conseguir su libertad individual. Las canciones representan un elemento más junto a las performances en directo o conciertos y la creación de contenido para redes sociales, como Instagram o YouTube, comentando las piezas y respondiendo a fans y youtubers. En este sentido, no queda en segundo plano cómo la artista se sirve de los elementos transmedia, desde una óptica de estrella del pop, hibridando medios, como muchos de sus videos, con lenguaje de Instagram... Representa un ejemplo modélico de "parafonografía", término que propone Serge Lacasse (2000) transfiriendo el concepto de Genette (1997) de paratexto a la producción de música popular, como una combinación de materiales donde se media la narrativa musical y que contempla los gráficos, textos, el trabajo de arte de la portada del disco, los cómics, las novelas gráficas, así como los conciertos, sus performances y la publicidad gráfica de los mismos (Burns, 2016). En este sentido, puede destacarse el cuidado concepto visual de otros materiales de presentaciones y publicitarios como la portada del disco y los gifs que acompañan a sus canciones -aún sin video-en YouTube, diseñados por el artista visual Filip Custic.

En primer lugar, como elemento de unidad específica del álbum, y rasgo que aparece presente en casi todos los vídeos, los motivos visuales recurrentes en numerosos momentos de los vídeos funcionan como un elemento de cohesión, actuando como leitmotivs. En segundo lugar, con frecuencia establecen una revisión de apropiación con significativos cuadros visuales reconocibles de la historia cultural/icónica española. Vamos a verlo.

La apropiación cultural, práctica mediática y artística que describe una operación posmoderna en relación con los procesos de creación, es un importante recurso de la visualidad contemporánea en todas sus manifestaciones, que compone procesos de reciclaje, circulación e hibridación cultural y consiste en retomar directamente referencias, imágenes de toda la tradición cultural anterior, repensarlas y presentarlas como propuesta, revisitando su significación, pero modificando elementos que aportan/suman otros sentidos o los resignifican. Así, la apropiación puede definirse 
[...] como un procedimiento por el cual una obra utiliza, cita, re-estructura, imágenes y/o sonidos de diversa procedencia. Es por tanto una forma de intertextualidad. [...] En la apropiación artística el gesto transgresor está en la reinvindicación de las imágenes como parte de nuestro entorno, de nuestra vida cotidiana, convirtiéndose por tanto en dominio público reutilizable. Hay que recordar que ésta es una realidad una práctica común en los medios masivos que se hace patente, por ejemplo, en el uso de imágenes recuperadas en videoclips, anuncios publicitarios, programas de televisión. (Rodríguez, 2010, pp. 145-146)

La apropiación niega ideas clásicas de la obra artística, como la autenticidad y la originalidad, propias de la concepción individualista de la creación que se forjó en el siglo XIX. Por el contrario, las prácticas intertextuales, como otras posmodernas, ponen en cuestión las ideas de autor $\mathrm{u}$ obra individual e imponen a los motivos visuales una reconfiguración continua según finalidades sociales o individuales.

El álbum de Rosalía lleva esta revisitación contemporánea hasta el kitsch, fenómeno de cita que actúa por acumulación de objetos con múltiples orígenes: el kitsch normalmente imita, pero exacerbando el resultado, sumando elementos para una visión recargada y no sublime de lo visual. Como movimiento estético, el kitsch queda hoy como una operación claramente posmoderna de cita, pero también de estilización y de estetización, criticado por todos los teóricos del movimiento (Debord, Foucault), aunque presente desde principios de siglo, como afirman las palabras de uno de sus máximos definidores: "La esencia del kitsch consiste en la substitución de la categoría ética con la categoría estética; impone al artista la obligación de realizar, no un 'buen trabajo' sino un trabajo 'agradable': lo que más importa es el efecto” (Broch, 1970, p. 9).

Para comprobar esta voluntad de apropiación directa solo es necesario repasar los videoclips que constituyen el álbum EMQ. En primer lugar, Malamente, parodiado, versionado y criticado numerosas veces, es un producto depurado de la factoría CANADÁ, empresa catalana de primer nivel como productora de videoclips: resulta un perfecto video conceptual-performance donde lo conceptual adquiere un peso específico, por la complejidad de la puesta en escena, con la formación de al menos cuatro tableaux 
vivants diferenciados (Figura 1). Al igual que en el cine primitivo, estos actúan como cuadros vivos, donde el discurrir temporal se visibiliza, pero donde el movimiento visual y de la cámara no se traduce en una función narrativa de desarrollo de la acción. En este caso, estos cuadros visuales resultan ejemplos singulares de proezas espaciotemporales, con VFX de tipo bullet time, efecto que popularizó la película Matrix (Hermanos Wachowski, 1999). Estos cuatro cuadros son: interiores de un espacio donde se encuentran niños o alumnos muy jóvenes de una escuela de toreo; exteriores de un espacio industrial, calles de polígono, gasolineras, parajes junto a descampados, calles sin salida o entre casas en ruinas, donde la protagonista se encuentra, escapa o baila, sola o junto a un grupo, y donde la cantante corre o lo hacen otros personajes; garaje; interior de un camión en movimiento, en hibridación con la parte performance.

\section{Figura 1. Fotogramas del videoclip Malamente (2018) y sus cuatro tipos de escenas}

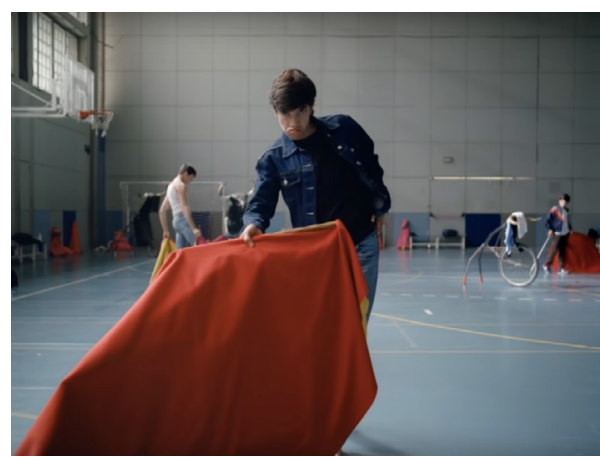

Interiores escuela de toreo.

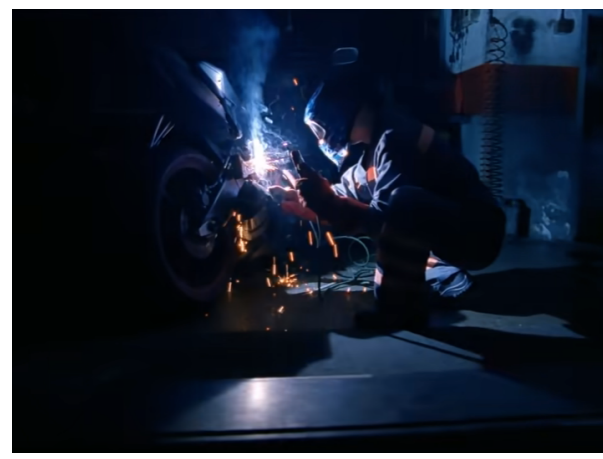

Garaje.

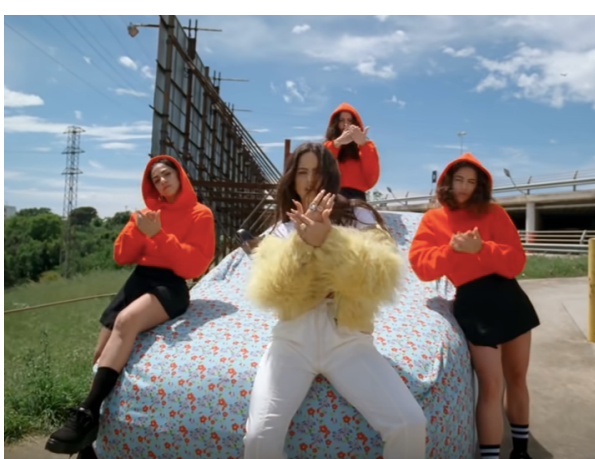

Exteriores de espacio industrial.

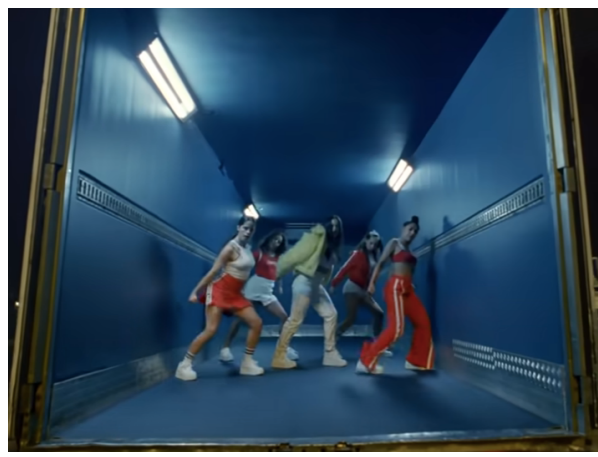

Interior de camión en movimiento.

Fuente: elaboración propia. 
Estos cuadros representan todo el escenario vital donde se desarrolla la problemática en que la protagonista dispone el concepto básico de la letra y que se resume en el título del capítulo: Augurio. A estas cuatro ambientaciones diferenciadas, que componen un espacio indeterminado, se suman variados personajes (un chico que corre -itras ella?-, un nazareno en patinete...) realizados con el recurso de cámara lenta para los pasajes donde no se produce performance: un modo de poblar un paisaje urbano indeterminado y abierto al significado.

Y es que lo que ofrece Malamente (y algunos otros vídeos de Rosalía) supone forzar el concepto de bodegón pictórico, tan en relación con el de tableau vivant, a la vez que se apela a la simbología española del interior doméstico antiguo, rancio, anticuado, y de otros espacios o acciones relacionados con el baile flamenco y el toreo, para desacralizarlos (Corazón, 2018): la apropiación que realizan estos videoclips actualiza este mundo visual iconográfico y, sobre todo, lo globaliza a través de contenidos visuales anexos -paratextuales- compartidos en redes sociales. Esta es la función de comparar toro y moto con la inclusión del joven torero capeando a la cámara y, más tarde, a la propia Rosalía en una motocicleta de alta cilindrada. Los tres planos brevísimos al final del segundo estribillo/comienzo de la sección del puente de la canción (lugar de la estructura de la letra que da comienzo a una especie de resolución visual del videoclip) resumen esta relación visual de ambigüedad que se propone en toda la pieza entre toro-moto, hombre-mujer y la iconografía masculina del poster pornográfico en el taller (Figura 2).

Pienso en tu mirá, segundo clip de EMQ se presenta como otra interesante propuesta de presentación del tipo de performance de la cantante en sus directos, con un grupo de bailarinas de fondo. Son de destacar las acciones de halago y vestimenta de la artista, donde ella se convierte en única persona reconocible entre todas las figuras que pueblan el encuadre. Por otro lado, se encuentran las múltiples referencias visuales a la letra, que ilustran con la representación de pasajes descritos en sus frases. Esta canción resulta el capítulo Celos, dentro del desarrollo emocional de línea argumental del disco, que, recordemos, se basa en el imaginario de la novela 


\section{Figura 2. Tres cuadros visuales antes del puente en el videoclip de Malamente (2018)}

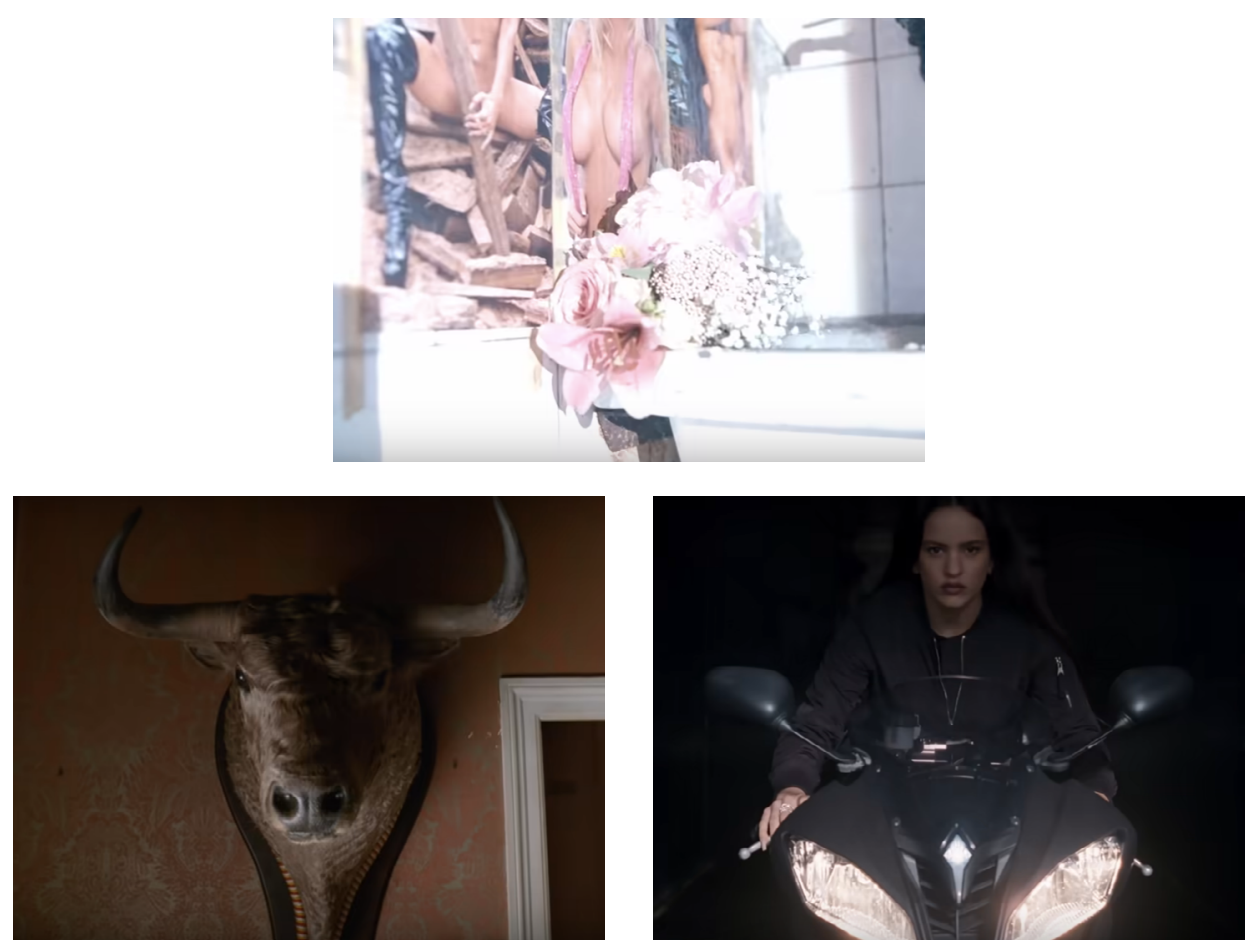

Fuente: elaboración propia.

anónima Flamenca, del siglo XIII y que repasa los diversos estadios emocionales de una pareja. De hecho, la letra comienza "me da miedo cuando sales, porque todos pueden ver los hoyuelitos que te salen"; unas palabras y sigue "(tengo miedo) y del oro que te viste, por amarrarse a tu cuello", mientras es vestida por un grupo de chicas, distinguidas solo por las manos. La frontalidad y gestualidad de Rosalía nos recuerdan la posición de la escultura religiosa española de Semana Santa o vírgenes de Gloria (Virgen del Rocío, por ejemplo) (Figura 3).

Una escena de violencia final que deja el interior del camión roto y la protagonista a salvo sobre él componen la resolución, abierta, de este episodio, en el que resuenan obras anteriores. Jamón Jamón (1992) de Bigas Luna es una película básica en el entendimiento de los símbolos patrios 
más recalcitrantes. El director se vale de símbolos como el jamón, el toro de Osborne y las planicies castellanas para contar esta historia pasional con triángulo amoroso entre personajes desaforados y final trágico: los protagonistas terminan violentamente, al modo en que fue representado por Goya en su Duelo a garrotazos (1819) y que Rosalía retoma en el final del capítulo cuando una figura masculina destroza el interior del camión en movimiento: una referencia a la violencia de género, tema presente desde la elección de la estructura narrativa por capítulos/fases de una relación amorosa tóxica, hasta este tipo de motivos o cuadros visuales concretos.

Respecto a otros elementos, deben ser destacados tres momentos, a modo de estructuración visual a lo largo del vídeo: la muñeca en la luna del coche (principio), el bodegón con figura de porcelana de la niña bailando (mediación del vídeo) y la figura de la cantante en contrapicado y contraluz, sobre el camión (final) (Figura 5).

\section{Figura 3. Comparación visual entre momentos de Pienso en tu mirá y la figura de la Virgen del Rocío}

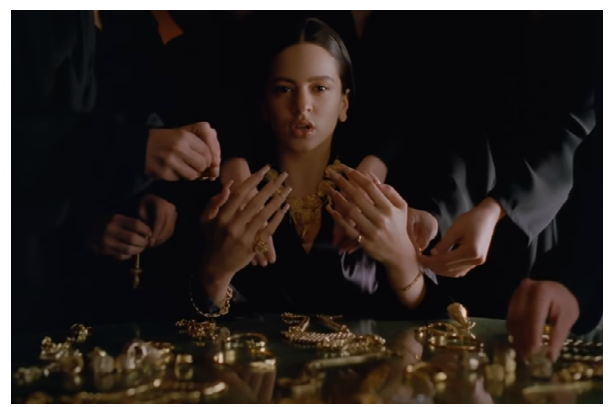

Fotograma del videoclip Pienso en tu mirá (2018).

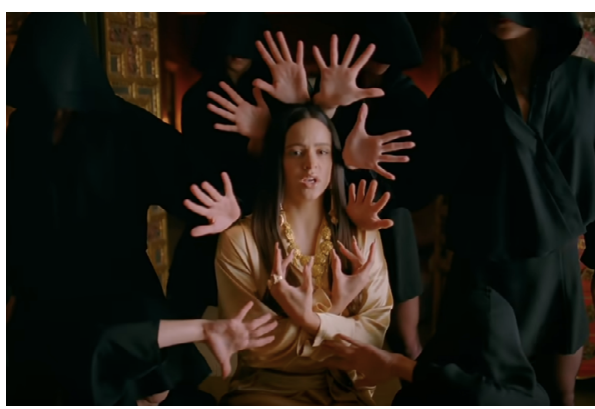

Fotograma del videoclip Pienso en tu mirá (2018).

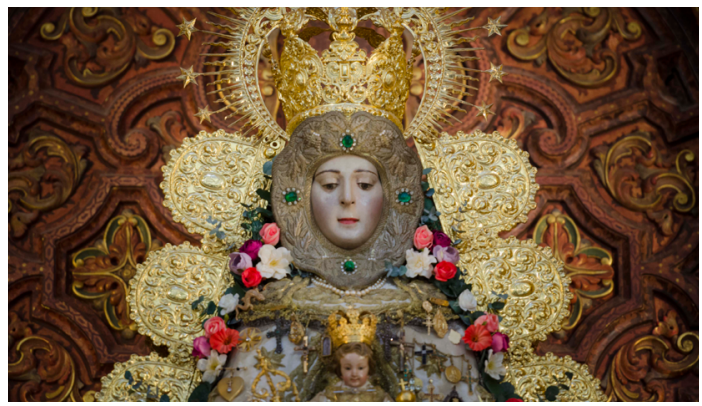

Virgen del Rocío (Almonte, Huelva, España).

Fuente: elaboración propia. 


\section{Figura 4. Apropiación de motivos clave de la tradición española}

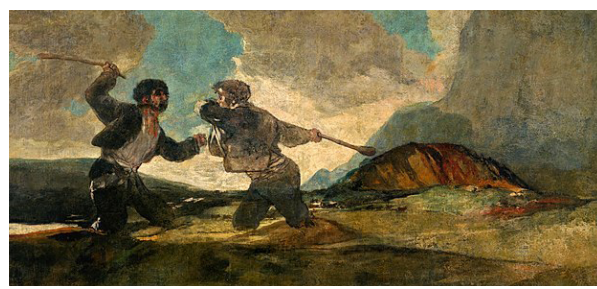

Duelo a garrotazos o La riña (Francisco de Goya, 1819).

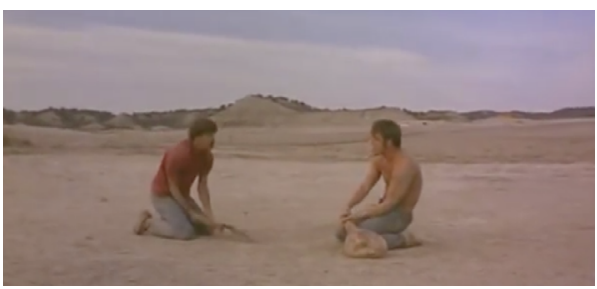

Jamón Jamón de Bigas Luna (1992).

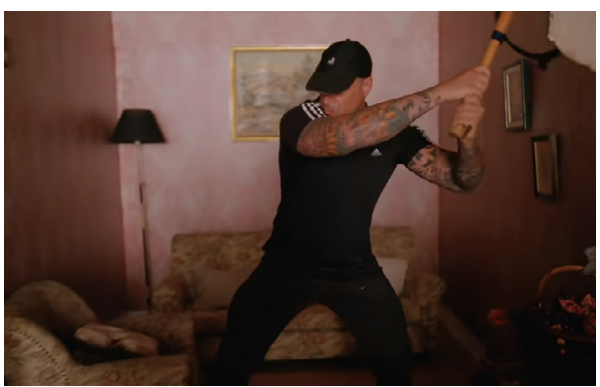

Fotograma del videoclip Pienso en tu mirá (2018).

Fuente: elaboración propia.

\section{Figura 5. Motivos visuales relacionados en Pienso en tu mirá}

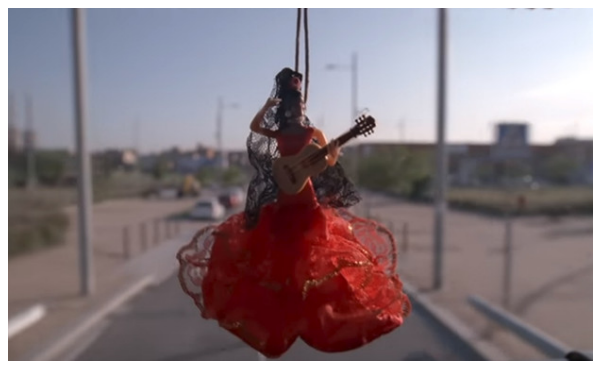

Principio: fotograma del videoclip Pienso en tu mirá (2018).

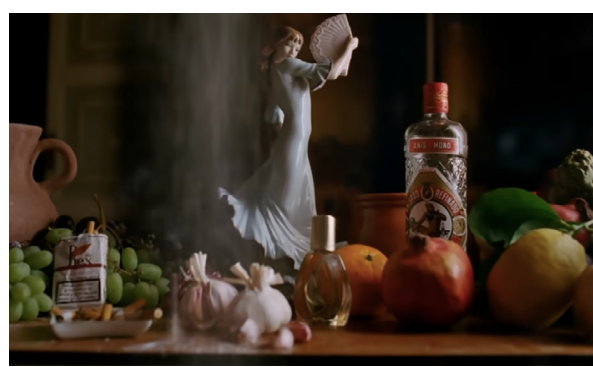

Mitad: fotograma del videoclip Pienso en tu mirá (2018).

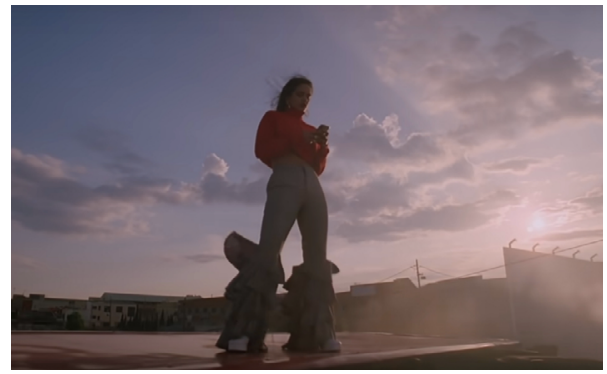

Final: fotograma del videoclip Pienso en tu mirá (2018).

Fuente: elaboración propia. 
En Di mi nombre, con una única localización, encontramos a la artista sobre una cama colocada en el centro de la habitación y decorada con cojines; en ella, se mueve y realiza su performance. El interior recargado y barroco es el único entorno de la performance: similar a Pienso en tu mirá, pero en esa ocasión el montaje cortaba a escenarios exteriores variados. En este caso, la referencia de apropiación más específica es La maja vestida de Goya, como puede observarse en la Figura 6.

\section{Figura 6. Disposiciones similares respecto a un momento de Di mi nombre}

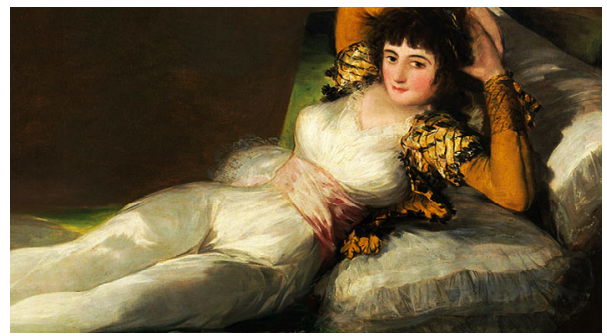

La maja vestida (Goya, 1800-1808).

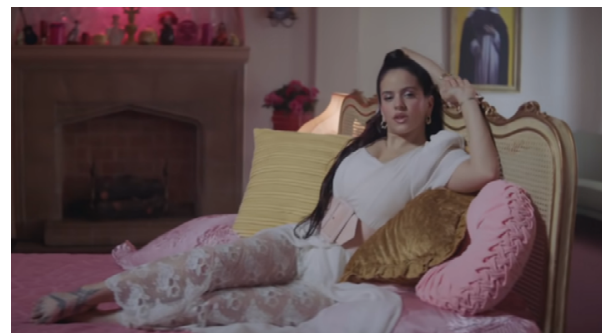

Un momento de Di mi nombre (2018).

Fuente: elaboración propia.

Siguiendo con el vídeo, supone casi un completo plano secuencia donde se repiten algunas ideas visuales anteriores: las chicas del cuerpo de baile, ocultas y anónimas, el movimiento en un espacio interior mediante la cámara en grúa de seguimiento de movimientos y coreografía solitaria de Rosalía. En este caso es destacable la realización de la cámara, que visualiza, en su devenir lateral, frases o motivos musicales breves de la melodía, especialmente instrumentales (no vocales), con lo cual genera ese sentido de continuidad que estaba en Malamente. Esta técnica permite la construcción de una propuesta de cierto sentido circular del espacio y el tiempo visual del vídeo, que comienzan y terminan con recursos complementarios y la misma posición de la intérprete (la correspondiente al cuadro de Goya), lo que no es un recurso tradicional del videoclip contemporáneo, en cuanto a lo circular y reiterativo o en loop de sus técnicas visuales.

De aquíno sales es la canción de estructura menos clásica y el videoclip más críptico y, en nuestra opinión, menos interesante o cerrado como tex- 
to audiovisual de Rosalía. En este clip se reitera el motivo motero, también en lo sonoro: esta vez, en principio, con una mínima expresión, pues solo se expresa en el sonido de esta máquina a gran velocidad, empleada como recurso técnico/expresivo, y en el motor que aparece junto a ella en el escenario principal del vídeo. Más tarde, como objeto que acompaña en el agua a Rosalía.

Sin embargo, el principal motivo del vídeo es la referencia a Ofelia y, en concreto, a la película Melancolía de Lars von Trier. Sin embargo, de nuevo el empleo alternativo de ciertas asociaciones de símbolos construye una contranarrativa: Rosalía parece querer decirnos que no se queda ella en este tiempo oscuro en que las mujeres mueren o languidecen en el río. Por el contrario, la artista surge del lago y vuelve a conducir una moto de gran cilindrada, como en la pieza Malamente.

\section{Figura 7. Comparación con obras pictóricas y cinematográficas de un cuadro visual de De aquí no sales}

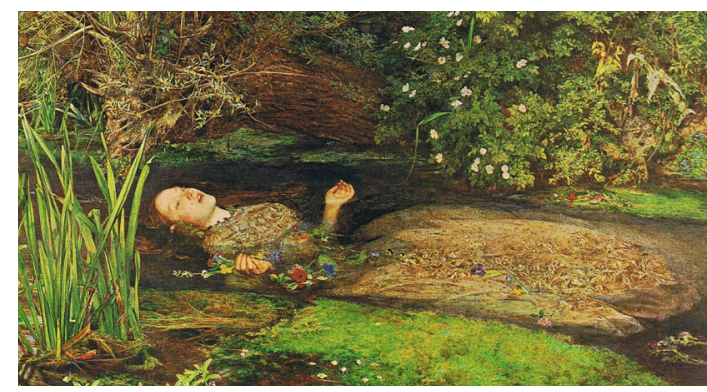

Ophelia de John Everett Millais (1852).

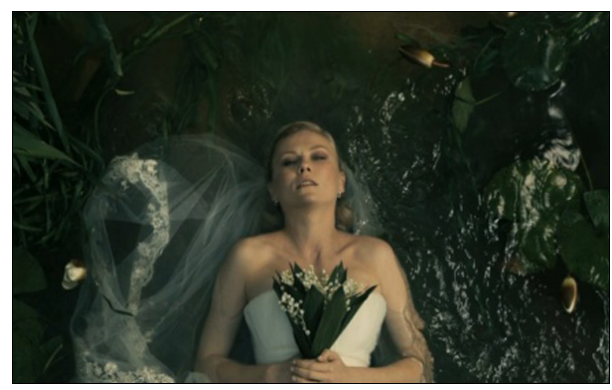

Melancholia de Lars von Trier (2011).

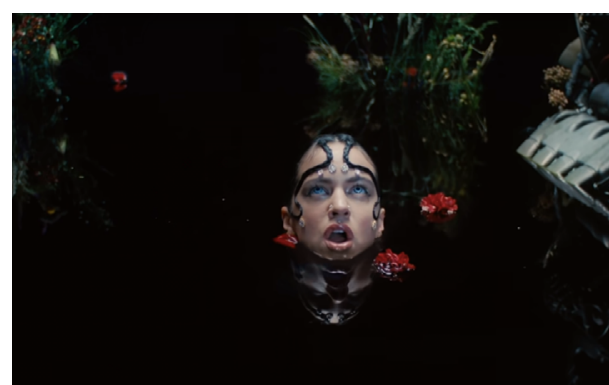

De aquí no sales de Rosalía (2018). 
Este trabajo de apropiación y cita continúa con EMQ en la dirección del discurso alternativo y contrahegemónico proveniente de la crítica feminista, representado por artistas plásticas y de performance que se han desarrollado y trabajan en España en los últimos años, como Pilar Albarracín, artista visual y de performance que retoma los motivos más rancios de la tradición española (ritos alimentarios, tradiciones populares...) para subvertirlos con el objetivo de denunciar la situación femenina. En trabajos como Musical Dancing Spanish dolls (2001) ubica con ironía un cuerpo de mujer entre muñecas, Barbies concretamente, con las que hace parodia de los movimientos y apariencia de la mujer en el espectáculo social. En She-Wolfs (2006) come junto a un lobo, tal como hace la figura femenina en De aquí no sales. Si en Malamente se establecía la relación toro/moto/figura femenina, en esta ocasión se configura la de lobo/moto/figura femenina.

\section{Figura 8. Rosalía y Pilar Albarracín}

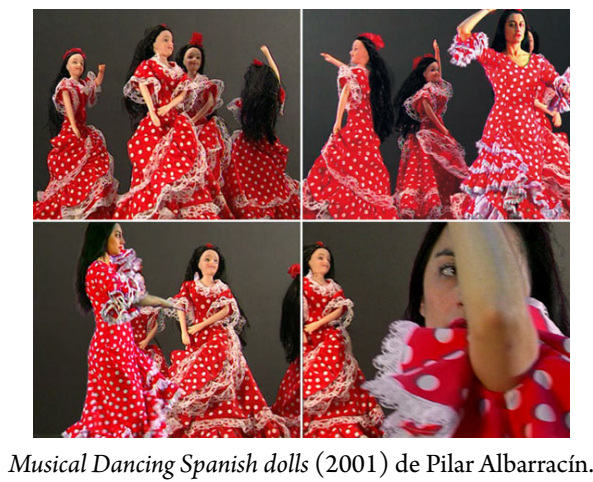

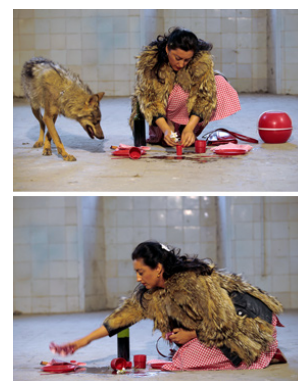

She-Wolfs (2006) de Pilar Albarracín.

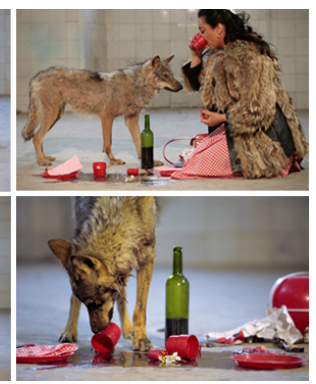

Fuente: elaboración propia.

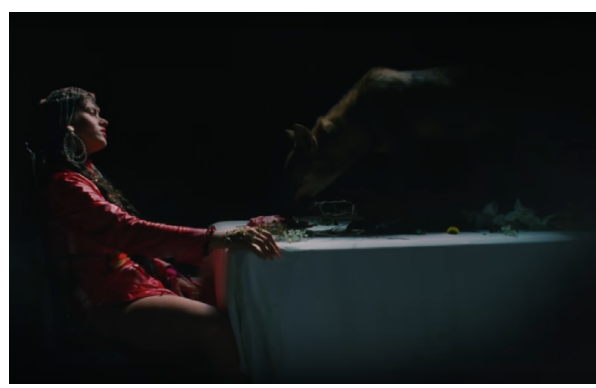

De aquí no sales (2018) de Rosalía. 
Otro tema resulta de las secciones del performance, que se distribuyen particularmente en los estribillos. No existe un corpus específico de análisis de la performance bailada en videoclips, si se exceptúan los trabajos de Mairs Slee (2017), Guarinos-Galán y Sedeño-Valdellós (2018), Philippa Thomas (2014) o Blanco Borelli (2012), aunque todos los análisis coinciden en la creciente importancia de la danza en la puesta en escena de los videoclips. De manera genérica, la performance bailada y el cuerpo del performer atraen el cuerpo del espectador a través de múltiples microformas de sincronización kinético-visual, con las que se articulan lo musical, lo visual y lo corporal. Con ello el espectador recibe e integra el texto vídeo de una manera sinestésica y somática, lo que se suma a funciones didácticas, de apropiación del discurso del artista o banda en cuestión, confluyendo en una vivencia o experiencia musical completa:

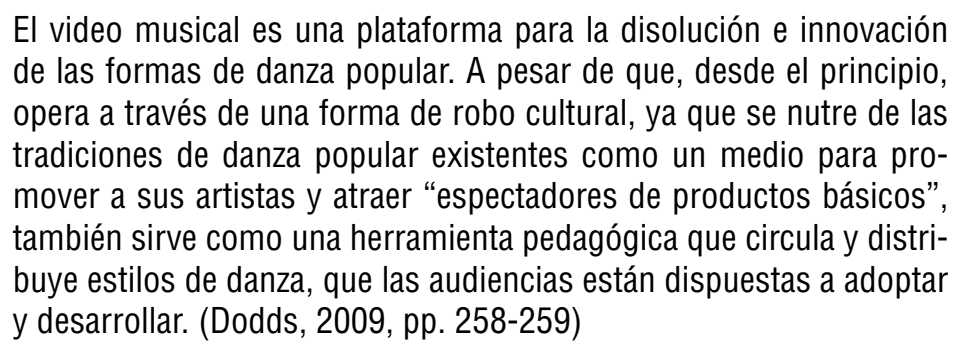

De alguna manera, este proceso vivencial resulta posible porque la música se encarna visualmente a través del baile. En las performances de artistas femeninas se ha establecido un componente de empoderamiento que se manifiesta en actitudes, formas y movimientos de cuerpo entero y brazos, composición de imagen, edición... La sincronía de estos elementos con los materiales sonoros de la música (ritmo, melodía y estructura) suele trabajarse desde los primeros momentos de conceptualización de la coreografía y del vídeo.

El baile en los videoclips de Rosalía se produce colectivamente, alternando el plano general y entero grupal y el plano medio y medio/corto definidos por la centralidad espacial de la artista en encuadre: en muchas ocasiones el paso de uno a otro a través de la edición reproduce un modelo clásico de montaje en movimiento que invisibiliza el corte entre accio- 
nes, aunque la no-modificación del punto de vista -colocación física de la cámara, en este caso, frontal del acto de danza- supone un elemento diferenciador respecto a la fórmula anterior y permite que los planos sean brevísimos y que combinen hasta cuatro momentos de performances bailadas como si fuesen uno (Figura 9). El contrapicado de la cámara se suma para posicionar centralmente en la mirada del espectador a la cantante, mientras la edición puntúa pasos coreográficos específicos cambiando de planos generales o americanos a planos medios. Esto supone un recurso acertado para los objetivos de fruición del vídeo: el espectador tiene que sentir la música.

\section{Figura 9. Continuidad entre planos por montaje en la performance de Malamente}
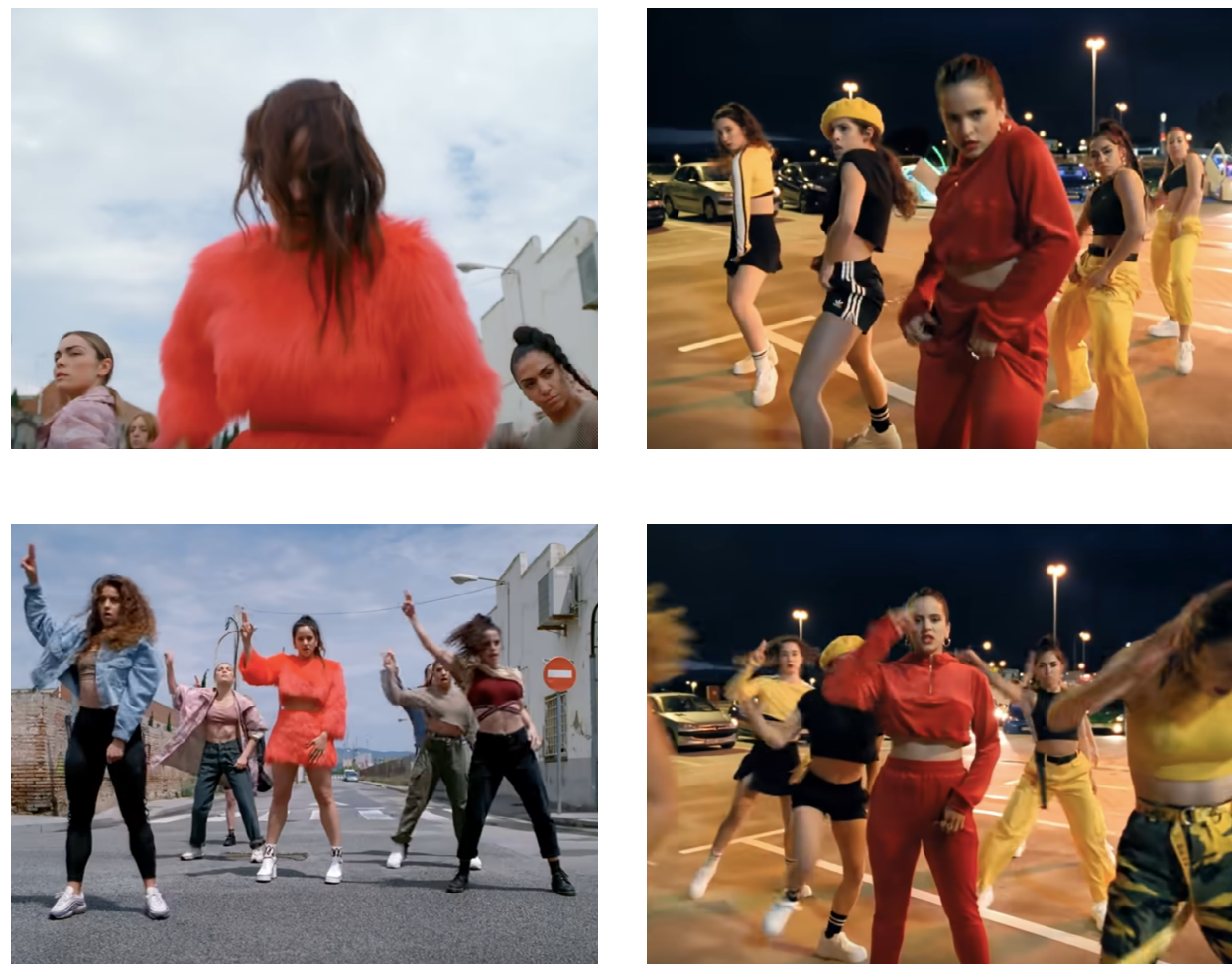

Fuente: elaboración propia.

Los videoclips de Rosalía suponen parte importante de su performance artística, tanto que su virtuosismo combina lo musical y lo vocal (sabe- 
mos que Rosalía es la compositora junto a El Guincho de música y letra de sus canciones), pero en el pop este virtuosismo está obligado a demostrarse en la performance, que debe dar forma a la innovación y autenticidad de lo popular, en cambio y transgresión constantes: la repetición durante los conciertos de las coreografías visualizadas anteriormente en los clips permite demostrar esa autenticidad específica.

Esta unión de performatividad bailada y un storyworld abierto y en construcción en torno a motivos visuales repetidos y reapropiados, ya vigentes en el imaginario español, es uno de los aciertos específicos del trabajo cultural que supone EMQ. Todo asegura una vasta repercusión en redes: la intercreatividad amateur del prosumer (professional + consumer), ya experto en labores de remontaje y participación, inspira coreografías profesionales o amateur provenientes de todo el mundo, tutoriales, parodias o reacciones de cientos de artistas. ${ }^{2}$

\section{Conclusiones}

Los proyectos transmedia se caracterizan por la creación de contenidos culturales mediados y gestionados a través de diversos canales y formatos. La modificación de la producción cultural después de la revolución digital construye nuevos vínculos entre los medios y sus formas de producir contenidos e introduce, además, un componente lúdico o participativo fundamental. Esto no deja fuera a la música, que ha estado siempre en el corazón de estos procesos: las experiencias musicales transmedia se encuadran en la función de creación de autenticidad y vivencia, propósito principal de cualquier herramienta comercial de la música popular.

El videoclip musical se ha constituido como formato de centralidad creciente en la cultura contemporánea, alcanzando cotas de influencia sobre el resto de géneros visuales: de ello resulta evidente que se emplee como género marco, intermedia, por su adaptabilidad a todos los canales, desde el que se planifican los procesos promocionales en la industria de la música.

2 Algunos ejemplos: Bill RoXenos (2019); BorjaRueda8 (2018); 4CM Dance Studio (2019); Place (2019); Los Morancos Oficial (2018). 
Sumando posibilidades para crear valor añadido, el álbum visual continúa en la senda de la construcción mediática de stardom, combinando procesos de unidad y heterogeneidad discursiva. En él todos los tracks tienen un vídeo y estos interactúan entre sí para la creación de un mensaje conceptual más amplio, complejo y abierto, una metanarrativa del artista y género musical: promoción global que organiza estrategias de exposición intermedial y transmedial repartidas en diversos medios. Los rasgos que animan a describir el proyecto $E M Q$ como álbum visual apuntan a esa capacidad de generar unidad y coherencia temática a través de motivos visuales, como ocurre en otros álbumes de artistas como Beyoncé, PJ Harvey...: ambientes o situaciones, personajes tipo y, sobre todo, algunos cuadros visuales que gravitan en o se heredan de la tradición visual española. Esto ha permitido a Rosalía componer una agencia temática específica respecto a una historia de amor violento, y dosificarla por episodios, los capítulos que subtitulan los nombres de las canciones/vídeo, como una novela por entregas.

Este uso de códigos iconográficos en apropiación llega mediante patrones, presentes en videoclips conceptuales desde siempre: híbridos entre una sección de performance -ubicados en escenarios que recrean lugares tipificados en el imaginario del género musical flamenco- $y$ motivos visuales con acciones atomizadas, donde los eventos no alcanzan lo narrativo, sino que construyen escenas representativas, a modo de fotos en movimiento o tableaux vivants. Su recurrencia los convierte en leitmotivs que jalonan los distintos vídeos e interconectan canciones, letras y contenidos, aportando ese continuo temático en lo visual y en lo sonoro que caracteriza al álbum visual y que permite la relación con contenidos anexos -paratextuales- en redes sociales y animan la intercreatividad de fans y espectadores: una creación de sentido y de concepto, de stardom, que media la exposición de la totalidad de la presencia como artista de Rosalía, combinando lo corporal y lo digital para permitir una conexión completa con el público/s. La industria musical aún mantiene en fase alpha y de prueba estas estrategias, reservadas para casos específicos; sin embargo, se contextualizan como una salida creciente en un entorno competitivo, de sobresignificación y saturación, como el de la música popular. 


\section{Referencias}

4CM Dance Studio (2019). Malamente-Rosalía/Yasmin Choreography. 11 de junio. Canal YouTube. https://www.youtube.com/ watch?v=GZ_o_qDMuAs

Ball, K. (2016). Beyonce's formation. Film Criticism, 40(3). DOI: http:// dx.doi.org/10.3998/fc.13761232.0040.309

Bill RoXenos (2019). Rosalía - MALAMENTE (DANCE PROJECT) BY BILL ROXENOs. 17 de abril. Canal YouTube. https://www.youtube.com/ watch?v=KlfgC_kn6to

Blanco Borelli, M. (2012). Dancing in music videos, or how i learned to dance like Jane... Miss Jackson. The International Journal of Screendance, 2, 52-55. Recuperado de: http://arts.brighton.ac.uk/projects/ screendance/the-international-journal-of-screendance\# page $=60$

BorjaRueda8 (2018). RosAlíA-Malamente I Borja Rueda Choreography. 1 junio. Canal YouTube. https://www.youtube.com/ watch?v=1B4nQQDmU5s

Broch, H. (1970). Kitsch, vanguardia y el arte por el arte. Barcelona: Tusquets.

Burns, L. A. (2016). The concept album as visual—sonic-textual spectacle: The Transmedial storyworld of Coldplay's Mylo Xyloto. Ispmjournal, 6(2), 91-116. Consultado en: http://www.iaspmjournal.net/index.php/IASPM_Journal/article/view/783

Carrera, P., Limón, N., Herrero, E. y Sainz de Baranda, C. (2013). Transmedialidad y ecosistema digital. Historia y Comunicación Social, 18, 535-545. DOI: http://dx.doi.org/10.5209/rev_HICS.2013. v18.44257

Chandler, D. y Munday, R. (2011). Motif. A dictionary of media and communication. Oxford-Nueva York: Oxford University Press. 
Corazón, A. (2018). Canada: "Rosalía ha desacralizado los símbolos, que es lo contrario de apropiárselos". Jotdown. Consultado en: https:// www.jotdown.es/2018/08/canada-rosalia-ha-desacralizado-lossimbolos-que-es-lo-contrario-de-apropiarselos/

Dixon, S. (2004). Digital performance: A history of new media in theater, dance, performance art and installation. Cambridge, MA: MIT Press.

Dodds, S. (2009). From Busby Berkeley to Madonna music video and popular dance. En J. Malnig (ed.), Ballroom, boogie, shimmy sham, shake: a social and popular dance reader. Chicago: University of Illinois Press.

Fairclough, K. (2018). Sountrack self: FKA twigs, music video and celebrity feminism. En G. Arnold, D. Cookney, K. Fairclough y M. N. Goddard (eds.), Music/video. histories, aesthetics, media (pp. 121131). Salford: Bloomsbury Academic.

Frith, S. (1988). Music for pleasure. Essays in the sociology of pop. Cambridge: Cambridge University Press.

Genette, G. (1997). Paratexts: Thresholds of interpretation. Cambridge: Cambridge University Press.

Goodwin, A. (1992). Dancing in the distraction factory: Music televisión and popular culture. Minneapolis: University of Minnesota Press.

Guarinos-Galán, V.y Sedeño-Valdellós, A. (2018). Danza contemporánea y sincronía musicovisual en el videoclip musical actual. Revista Mediterránea de Comunicación, 9(2), 321-332. DOI: https://www. doi.org/10.14198/MEDCOM2018.9.2.3

Hansen, K. A. (2017). Empowered or objectified? Personal narrative and audiovisual aesthetics in Beyoncés partition. Popular Musices Society, 40(2), 164-180. DOI: https://doi.org/10.1080/03007766 .2015 .1104906 
Harrison, C. (2014). The visual album as a hybrid art-form: A case study of traditional, personal, and allusive narratives in Beyoncé. [Master's Thesis] Visual Culture, Department of Arts and Cultural Sciences, Lunds University, Lunds.

Hawkins, S. y Richardson, J. (2014). Remodeling Britney Spears: Matters of intoxication and mediation. Popular Music and Society, 30(5), 605-609. DOI: https://doi.org/10.1080/03007760600881359

Herman, D. (2009). Basic elements of narrative. West Sussex: Wiley-Blckwell.

Kleiler, D. y Moses, R. (1997). You stand there: making music video. Nueva York: Three Rivers Press.

Mairs Slee, S. (2017). Moving the music: Dance, action and embodied identities in music video. En G. Arnold, D. Cookney, K. Fairclough, M. N. Goddard (eds.), Music/video. Histories, aesthetics. Salford: Bloomsbury Academic.

Lacasse, S. (2000). Intertextuality and hypertextuality in recorded popular music. En M. Talbot (ed), The musical work: Reality or invention? (pp. 35-58). Liverpool: Liverpool University Press.

Leguizamón, J. A. (1998). Videoclips: una exploración en torno a su estructuración formal y funcionamiento sociocultural. [Tesis doctoral] Universidad Nacional de Santiago del Estero, Santiago del Estero. Consultado en: http://xurl.es/wwlwy

Letts, M. T. (2010). Radiohead and the resistant concept album: How to disappear completely. Bloomington: Indiana University Press.

Lizarazo Arias, D. (2004). Iconos, figuraciones, sueños. Hermenéutica de las imágenes. México: Siglo XXI.

Los Morancos Oficial (2018). Malamente-Rosalía | Los Morancos (Parodia). 20 de septiembre. Canal YouTube. https://www.youtube.com/ watch?v=9L3dwNAsbxw\&ab_channel=LOSMORANCOSOFICIAL 
Perrott, L., Rogers, H. y Vernallis, C. (2016). Beyoncé’s Lemonade: She dreams in both worlds. Film International Online, 2. Recuperado de http://filmint.nu/?p=18413

Place (2019). Malamente | Rosalía - Choreography by Julie B. 12 marzo. Canal YouTube. https://www.youtube.com/watch?v=U90DhfGkoOg

Rodríguez-Mattalia, L. (2010). Videografía y arte: indagaciones sobre la imagen en movimiento. Castellón: Ars Universitat Jaume I.

Sedeño-Valdellós, A. M. (2016). El álbum visual como nueva forma promocional de la industria de la música: el caso de Let England Shake de PJ Harvey y Seamus Murphy. Palabra Clave, 19(1), 105-132. DOI: https://doi.org/10.5294/pacla.2016.19.1.5

Thomas, P. (2014). Single ladies, plural: Racism, scandal, and "authenticity" within the multiplication and circulation of online dance discourses. En M. Blanco Borelli (ed.), The Oxford Handbook of Dance and Popular Screen (pp. 289- 303). Nueva York: Oxford University Press.

Vernallis, C. (2008). Music video, songs, sound: Experience, technique and emotion in Eternal Sunshine of the Spotless Mind. Screen, 49(3), 277297. DOI: https://doi.org/10.1093/screen/hjn036 